\title{
BULLYING BEHAVIOR AND MENTAL HEALTH IN HEALTHCARE AND EDUCATIONAL SECTORS IN KAUNAS, LITHUANIA
}

\author{
${ }^{1}$ Lithuanian University of Health Sciences, Kaunas, Lithuania \\ Institute of Cardiology, Department of Population Studies \\ ${ }^{2}$ Lithuanian University of Health Sciences, Kaunas, Lithuania \\ Academy of Medicine, Department of Environmental and Occupational Medicine \\ ${ }^{3}$ Lithuanian Sports University, Kaunas, Lithuania \\ Department of Health, Physical and Social Education \\ ${ }^{4}$ Lithuanian University of Health Sciences, Kaunas, Lithuania \\ Academy of Medicine, Department of Internal Diseases
}

\begin{abstract}
Background: Investigations on workplace bullying in the countries of Eastern Europe are yet not too extensive. The aim of the study has been to identify the most frequent bullying behavior and to explore the associations with psychological distress and post-traumatic stress symptoms in 3 female-dominated occupations in Kaunas, Lithuania. Material and Methods: This crosssectional study employed 517 teachers (response rate $(\mathrm{RR})=71.3 \%), 174$ family physicians $(\mathrm{RR}=65.7 \%)$ and 311 internal medicine department nurses $(\mathrm{RR}=69.1 \%)$. The twenty-two-item Negative Acts Questionnaire was used for measuring the exposure to bullying behavior, Goldberg 12-item General Health Questionnaire (GHQ-12) - psychological distress, Event Scale-Revised (IES-R) inventory - post-traumatic stress symptoms, Karasek \& Theorell Demand-Control questionnaire - psychosocial job characteristics. The International Business Machines Corporation (IBM) SPSS Statistics version 20.0 was used for performing the statistical analysis. Logistic regression was used for assessing the associations among 22 negative acts as continuous variable and mental health outcomes adjusting to age, psychosocial factors at work and everyday life. Results: Exposure to workplace bullying behavior on a weekly/daily basis was prevalent among family physicians at the rate of $19 \%$, among nurses - $12.9 \%$, among teachers $-4.1 \%$. Even after adjustment to age, psychosocial job characteristics and threatening life events, the exposure to 22 negative acts as continuous variable was significantly associated with psychological distress and post-traumatic stress symptoms for all 3 occupations. Conclusions: Health care sector is particularly affected by workplace bullying. Exposure to bullying behavior was associated with mental health problems for all 3 occupations. Preventive measures are necessary to improve psychosocial work environment conditions in healthcare and educational institutions in Lithuania. Med Pr 2017;68(3):307-314
\end{abstract}

Key words: nurses, teachers, psychological distress, bullying behavior, family physicians, negative acts

Corresponding author: Lina Bernotaite, Lithuanian University of Health Sciences, Institute of Cardiology,

Department of Population Studies, Sukileliu av. 15, Kaunas 50009, Lithuania, e-mail: lbernotaite@alumni.unav.es

Received: May 25, 2016, accepted: February 23, 2017

\section{INTRODUCTION}

Workplace may impact an employee's mental health positively through the feeling of being meaningful for society, social support, but may also act conversely by contributing to the development of mental health problems [1]. Research has shown that workplace bullying is a severe social stressor and reduces the psychological and physical health of victims [2]. The prolonged exposure to bullying behavior is a predictor of psychological distress [3] and is even related to symptomatology specific for post-traumatic stress [4]. The definition of work- place bullying provided by Einarsen et al. [5] describes it as harassing, offending or socially excluding someone or negatively affecting someone's work behavior, that occurs repeatedly and regularly, e.g., weekly and lasts for a period of time, e.g., about 6 months. Bullying is also often described as a long lasting and gradually escalating process where frequent and ever more intense negative acts are directed towards a peer or a subordinate and leads the respondent to victimization [6].

The prevalence of bullying ranges from $4 \%$ in Northern to $17 \%$ in Southern Europe. This variation could be explained by cultural differences, diverse level of 
knowledge of the phenomenon, the inconsistency of bullying measurement methods and the variety of instruments used worldwide $[7,8]$.

Generally, 2 different methods to assess the prevalence of bullying are employed by researchers:

- the self-labelling approach where the respondent is requested to indicate whether she/he has felt being exposed to bullying at work within the last 6 months on the basis of the provided definition of workplace bullying,

- the "operational" approach which measures how frequently the respondent has been subjected to various types of bullying behavior presented in the inventory during the last 6 months without having referred it to the concept of bullying - exposure to bullying is then assessed by defining a criterion whether the respondent is regarded as bullied or not, e.g., at least 2 (Mikkelsen and Einersen (2011) [9]) negative acts per week during the last 6 months.

In this article terms: bullying behavior and negative acts will be used interchangeably.

The sectors with high level of contact with external customers, such as healthcare and education, tend to have the highest levels of workplace violence and are very often female-dominated $[2,10]$.

To be able to develop preventive strategies that would improve working conditions in terms of undesirable behavior at work, it is necessary to gain more detailed understanding of the phenomenon. The investigations on workplace bullying are yet not too extensive in Eastern European countries. This study has aimed to lessen the gap in this field of occupational epidemiology and to:

assess the level of an employee's exposure to negative acts most frequently identified with bullying (bullying behavior) in 3 female-dominated occupations within healthcare and educational sectors in Kaunas, the second largest city of Lithuania,

- examine whether there are differences in the prevalence of bullying behavior among investigated occupations,

identify who in the organizational hierarchy are the most frequent perpetrators in every examined occupation,

assess whether the associations among 22 negative acts might be influenced by other stressful exposures at workplace and everyday life, taking into account possible effects from high job demands, low job control, low social support at work, threatening life events and age in three investigated occupations.

\section{MATERIAL AND METHODS}

This cross-sectional study was approved by the Kaunas Regional Biomedical Research Ethics Committee (No. BE-2-12) and was carried out in 2015 for the sample of Kaunas employees representing 3 occupations teachers, family physicians and nurses, that was representative in terms of place of employment.

The sample consisted of:

- 517 teachers from 13 secondary education schools (the response rate of 71.3\%). The mean age of participants was 49.92 years old (the standard deviation $(\mathrm{SD})=9.11), 419(81 \%)$ were female and $41(7.9 \%)$ were male, $57(11 \%)$ respondents did not declare their gender, 42 (8.12\%) did not declare their age;

174 family physicians from 5 public and 5 private out-patient clinics (the response rate of $65.7 \%$ ). The mean age of the participants was 52.46 years old $(\mathrm{SD}=9), 144(82.8 \%)$ were female and $30(17.2 \%)$ were male;

- 311 internal medicine department nurses from 3 hospitals (the response rate of 69.1\%). The mean age of participants was 46.65 years old $(\mathrm{SD}=8.98)$, $310(99.7 \%)$ were female and $1(0.3 \%)$ was male, $26(8.4 \%)$ respondents did not indicate their age.

The survey was based on a self-administered anonymous questionnaire, which included demographic measures and globally used questionnaires, translated and validated for usage in Lithuania.

The Lithuanian version of the 22-item Negative Acts Questionnaire (NAQ) (Einarsen et al.) was used for assessing the variety of negative behavior forms [11]. It contains 22 items that represent the person-oriented and work-oriented negative acts and physical intimidation. The respondents are asked to indicate how often they have experienced each behavior during the last 6 months, using a 5-point Likert-type scale (where: 5 = daily, $4=$ weekly, $3=$ monthly, $2=$ now and then, and $1=$ never). The Negative Acts Questionnaire is the most widely used instrument for measuring exposure to workplace bullying and it is proven that its psychometric quality is good $[11,12]$. We used the operational approach and the exposure criteria proposed by Mikkelsen and Einarsen's (2001) [9]. The respondents were also asked to indicate the source of bullying.

Psychological distress was measured by Goldberg 12-item General Health Questionnaire (GHQ-12) which is a well-established self-administered screening scale for the evaluation of psychological distress in non-clinical population samples, valued for its excel- 
lent screening performances and good clinical validity in terms of diagnosing mental disorders and measuring general psychological well-being [12]. Three and more positive answers were assessed as psychological distress. Cronbach's a was 0.81 for family physicians, 0.83 - for nurses and 0.75 - for teachers.

Current subjective distress for a traumatic event was assessed using the Impact of Event Scale-Revised (IES-R) inventory [13]. It is a self-report measure scale adapted for usage in Lithuania that contains 22-items and assesses 3 categories of post-traumatic stress symptoms: hyper arousal, avoidance behavior and intrusive thoughts and/or feelings with reference to the past 7 days. Scoring over 33 was considered as a cut-off for a "probable post-traumatic stress disorder (PTSD) case" [14]. Internal consistency for the total IES-R scale was high (Cronbach's $\alpha$ for family physicians and nurses $=0.96$, for teachers $=0.95$ ).

Psychosocial job characteristics were measured by the Swedish version of Karasek \& Theorell DemandControl questionnaire translated and validated for usage in Lithuania. It consists of 6 items for assessing job control, psychological demands (5-items), supervisor support and coworker support (6-items) [15]. High and low categories for job demands, job control, and social support were determined by a cut-off point corresponding to the median of the total score for each of these constrains. Scores below the median were assessed as "low."

Participants were asked about the occurrence of threatening life events in the past 12 months that were associated with a long-term psychological threat: unemployment, divorce, financial crisis, death of a first degree relative or a close friend.

The study data was analyzed using the IBM SPSS Statistics version 20.0. Comparisons of mean scores of the responses to every NAQ-22 question across 3 occupations were performed by one-way ANOVA with post hoc Bonferroni correction, $\mathrm{p}<0.05$ was considered statistically significant. Other statistical procedures employed were: the frequency, $\mathrm{Chi}^{2}$ tests with $\mathrm{p}$-values and logi- stic regression analysis to investigate the associations between exposure to 22 negative acts as continuous variable and mental health outcomes (psychological distress and post-traumatic stress symptoms) adjusting to age in the first model and in the second model adjusting to age, dichotomized below the medium psychosocial job characteristics (job demands, job control, social support) and threatening life events.

\section{RESULTS}

Study results revealed that the highest prevalence of bullying behavior was detected in the healthcare sector while among teachers it was 3-5-fold lower as compared to nurses and family physicians (Table 1 ).

One-way ANOVA with post hoc Bonferroni correction investigated the differences in the mean scores of the responses to every NAQ-22 item among 3 occupations. The Table 2 contains 22 bullying acts ranked according to their mean values, i.e., their frequency of occurrence. The test showed that the differences between responses in 3 occupational groups to all items but one ("Hints or signals from others that you should quit your job” (10)) were significant. In general the greatest differences between the groups were observed for work-oriented items: "withholding information" (1), $\mathrm{F}(2,999)=40.377$, "pressure not to claim" (19), $\mathrm{F}(2,999)=37.918$, "unmanageable workload" (21), $\mathrm{F}(2,999)=35.360$, etc. The differences between the groups for the person-oriented negative acts were somewhat lower.

The Table 3 contains the data for the status of bullying perpetrators. Family physicians experienced bullying behavior from their superiors most frequently, meanwhile in the group of nurses peers tended to bully somewhat more often than superiors. The prevalence of bullying by external customers - patients/students, was similar in all 3 occupations. Teachers were offended by students most frequently.

The results of this study showed that respondents who were exposed to workplace bullying behavior re-

Table 1. Prevalence of being exposed to bullying behavior during the last 6 months in investigated female-dominated occupations in Kaunas, Lithuania

\begin{tabular}{|c|c|c|c|}
\hline $\begin{array}{l}\text { Negative acts } \\
\text { [n/week] }\end{array}$ & $\begin{array}{l}\text { Family physicians } \\
{[\mathrm{n}(\%)]}\end{array}$ & $\begin{array}{l}\text { Nurses } \\
{[\mathrm{n}(\%)]}\end{array}$ & $\begin{array}{l}\text { Teachers } \\
{[\mathrm{n}(\%)]}\end{array}$ \\
\hline $0-1$ & $141(81.0)$ & $271(87.1)$ & $496(95.9)$ \\
\hline
\end{tabular}

$\mathrm{Chi}^{2}=40.441, \mathrm{p}<0.001$. 
Table 2. Mean ranks of Negative Acts Questionnaire [11] in female-dominated occupations in Kaunas, Lithuania (one-way ANOVA with post hoc Bonferroni correction)

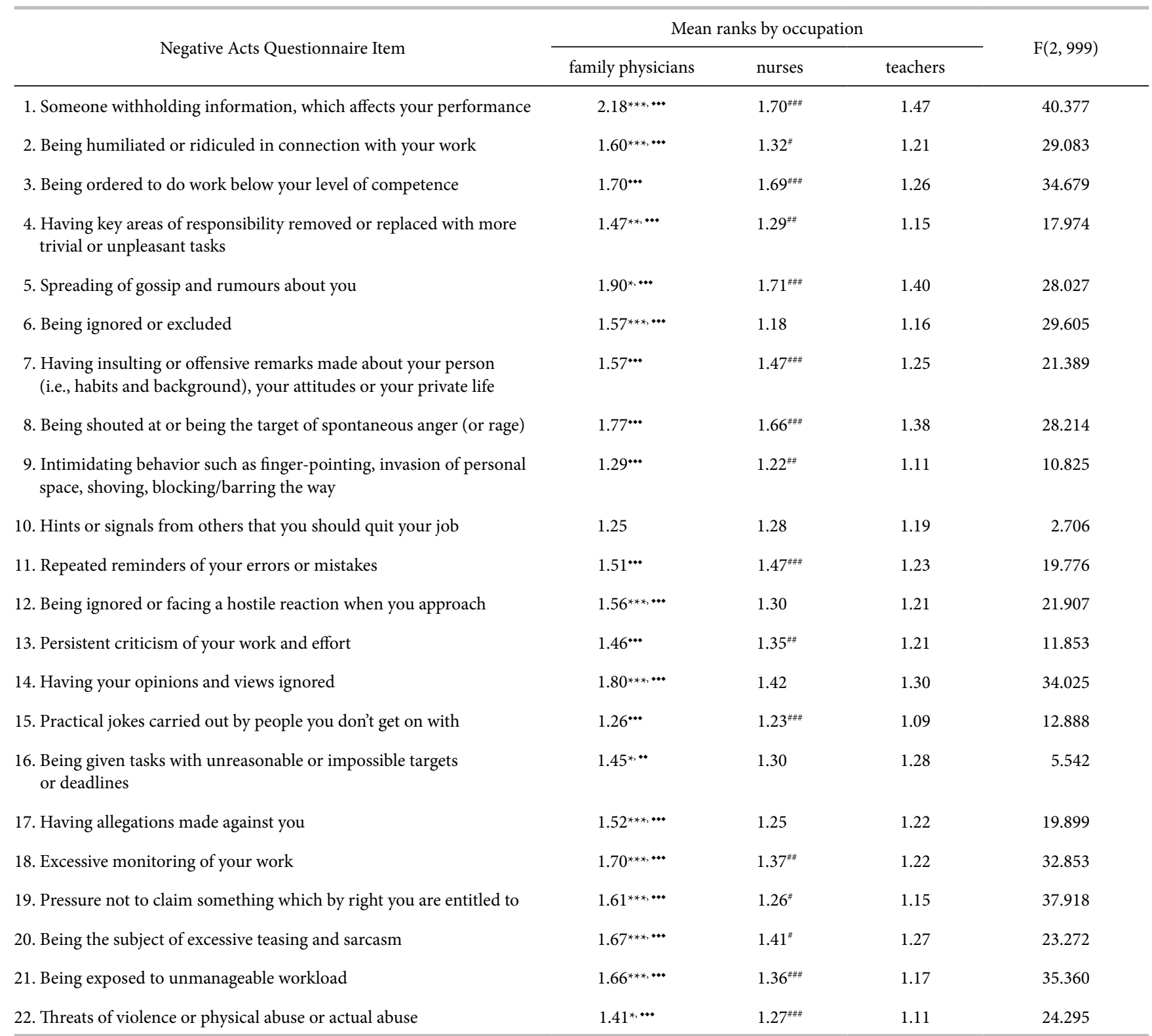

$\mathrm{F}(2,999)-\mathrm{F}$ statistics (degrees of freedom).

${ }^{*} \mathrm{p}<0.05,{ }^{* *} \mathrm{p}<0.01,{ }^{* * *} \mathrm{p}<0.001$, comparing data of family physicians and nurses.

• $\mathrm{p}<0.05, \cdots p<0.01, \cdots p<0.001$, comparing data of family physicians and teachers.

" $\mathrm{p}<0.05,{ }^{* * *} \mathrm{p}<0.01,{ }^{* * *} \mathrm{p}<0.001$, comparing data of nurses and teachers.

Table 3. Status of bullying perpetrator in investigated female-dominated occupations in Kaunas, Lithuania

\begin{tabular}{|c|c|c|c|c|c|c|}
\hline Bullying perpetrator & $\begin{array}{l}\text { Family physicians } \\
{[\mathrm{n}(\%)]}\end{array}$ & $\begin{array}{l}\text { Nurses } \\
{[\mathrm{n}(\%)]}\end{array}$ & $\begin{array}{l}\text { Teachers } \\
{[\mathrm{n}(\%)]}\end{array}$ & $\mathrm{Chi}^{2}$ & $\mathrm{df}$ & $\mathrm{p}$ \\
\hline Superior & $44(25.3)$ & $48(15.4)$ & $34(6.6)$ & 44.384 & 2 & $<0.001$ \\
\hline Colleague & $17(9.8)$ & $54(17.4)$ & $19(3.7)$ & 44.299 & 2 & $<0.001$ \\
\hline Subordinate & $5(2.9)$ & $11(3.5)$ & $2(0.4)$ & 12.190 & 2 & $<0.010$ \\
\hline Patients or students & $18(10.3)$ & $28(9.0)$ & $59(11.5)$ & 1.268 & 2 & 0.530 \\
\hline
\end{tabular}

$\mathrm{df}$ - degrees of freedom. 
ported significantly $(\mathrm{p}<0.05)$ more mental health complains than employees not subjected to bullying behavior (Table 4). In the group of family physicians the dichotomized association between workplace bullying behavior and psychological distress was insignificant, though in the logistic regression model the continuous associations were significant.

The Table 5 presents the associations between exposure to 22 negative acts as continuous variable and mental health outcomes (psychological distress and post-traumatic stress symptoms) adjusting to age in the first model and in the second model - adjusting to age, dichotomized below the medium psychosocial job characteristics (job demands, job control, social support) and threatening life events.

In the final model the associations between exposure to 22 negative acts and mental health outcomes remained stable in all 3 occupations.

\section{DISCUSSION}

The aim of this study has been to assess the prevalence of workplace bullying using the "operational" method, to identify the most frequent bullying behavior and to explore the associations between the exposure to workplace bullying behavior and mental health - psychological distress and post-traumatic stress symptoms in 3 female-dominated occupations (healthcare and education sectors) in Kaunas (Lithuania) taking into account the possible effects of age, adverse psychosocial job characteristics (high job demands, low job control, low social support at work) and threatening life events. We have also aimed to reveal the sources of bullying within every investigated sample.

Ourstudy results revealed that workplacebullying was prevalent for all 3 occupations; however the prevalence in the healthcare sector was much higher - 19\% among

Table 4. Association between experiencing negative acts and mental health in investigated female-dominated occupations in Kaunas, Lithuania

\begin{tabular}{|c|c|c|c|c|c|c|c|c|}
\hline \multirow{2}{*}{$\begin{array}{c}\text { Occupation } \\
\text { and negative acts }\end{array}$} & \multicolumn{2}{|c|}{$\begin{array}{l}\text { Post-traumatic stress symptoms } \\
\qquad[\mathrm{n}(\%)]\end{array}$} & \multirow{2}{*}{$\mathrm{Chi}^{2}$} & \multirow{2}{*}{$\mathrm{p}$} & \multicolumn{2}{|c|}{$\begin{array}{l}\text { Psychological distress } \\
{[\mathrm{n}(\%)]}\end{array}$} & \multirow{2}{*}{$\mathrm{Chi}^{2}$} & \multirow{2}{*}{$\mathrm{p}$} \\
\hline & no & yes & & & no & yes & & \\
\hline Family physicians & & & 18.383 & $<0.0001$ & & & 0.296 & 0.5870 \\
\hline $0-1$ acts/week & $122(87)$ & $18(55)$ & & & $80(82)$ & $61(79)$ & & \\
\hline Nurses & & & 6.992 & 0.0080 & & & 12.377 & $<0.0001$ \\
\hline $0-1$ acts/week & $243(89)$ & $28(74)$ & & & $214(91)$ & $53(75)$ & & \\
\hline 2-22 acts/week & $30(11)$ & $10(26)$ & & & $22(9)$ & $18(25)$ & & \\
\hline Teachers & & & 44.076 & $<0.0001$ & & & 30.215 & $<0.0001$ \\
\hline
\end{tabular}

Table 5. Associations between exposure to 22 negative acts as continuous variable and mental health in the logistic regression models in investigated female-dominated occupations in Kaunas, Lithuania

\begin{tabular}{|c|c|c|c|c|}
\hline \multirow{2}{*}{ Occupation } & \multicolumn{2}{|c|}{ Psychological distress } & \multicolumn{2}{|c|}{ Post-traumatic stress symptoms } \\
\hline & $\mathrm{OR}(95 \% \mathrm{CI})^{\star}$ & OR $(95 \% \mathrm{CI})^{\star *}$ & $\mathrm{OR}(95 \% \mathrm{CI})^{\star}$ & OR $(95 \% \mathrm{CI})^{\star *}$ \\
\hline Family physicians & $1.03(1.00-1.06)$ & $1.01(0.98-1.04)$ & $1.08(1.04-1.12)$ & $1.10(1.05-1.14)$ \\
\hline Nurses & $1.08(1.05-1.12)$ & $1.05(1.02-1.09)$ & $1.06(1.03-1.09)$ & $1.01(1.01-1.07)$ \\
\hline Teachers & $1.07(1.04-1.10)$ & $1.03(1.00-1.07)$ & $1.11(1.07-1.15)$ & $1.06(1.02-1.11)$ \\
\hline
\end{tabular}

OR - odds ratio, CI - confidence interval.

* Age adjusted.

** Adjusted to age, job demands, job control, social support at work, threatening life events. 
family physicians and $12.9 \%$ - among nurses compared to $4.1 \%$ among secondary school teachers. The data obtained from 5th European Working Conditions Survey conducted in 2010 showed that the prevalence of workplace bullying was $11.3 \%$ among the employees in the healthcare sector [7].

The research on workplace bullying solely among physicians is rather limited as compared to the extent of the investigations in the samples of nurses or healthcare sector in general. The research conducted on the samples of the emergency department physicians, medicine students alert that workplace violence in the healthcare field is a widespread problem $[16,17]$. In Ireland even $30 \%$ of surveyed junior doctors reported to be subjected to one or more bullying behavior [18]. The results of the study conducted on the sample of medicine students in the U.S. noted that the students particularly embarking on careers in family medicine claimed higher levels of harassment [19]. The prevalence that we found among Kaunas family physicians at the rate of $19 \%$ is very high; hence it requires further in-depth investigations to explore the root cause.

The results of the study carried out in the State of Washington, the USA, revealed that nearly every 3rd nurse (27.3\%) had experienced workplace bullying during the last 6 months and most of the respondents who had been bullied declared that they had experienced hostile behavior from their superiors [20]. Another study conducted in the USA by Berry et al. [21] on the sample of novice nurses showed that every 5 th of them (21.3\%) had been bullied daily during the last 6 months as assessed by the Negative Acts Questionnaire and the primary source of bullying came from the more experienced colleagues (63\%). In our study we have found that nurses are offended by peers somewhat more frequently than by superiors (17.4\% vs. $15.4 \%)$. The most frequent bullying behavior experienced on a daily or weekly basis by nurses in our study is work-related, e.g., "withholding information" (1) - 6.4\%, "work below your level of competence" (3) $-7.7 \%$. Similar findings have been identified in the Danish sample of hospital staff that has comprised mainly nurses and in the representative sample of Norwegian work force where the most prevalent negative acts reported include "work below your level of competence" (3) and "withholding information" (1) [9,22]. In the study carried out in the sample of Spanish nurses, the most frequently reported negative acts are also work-oriented [23].

Studies on workplace bullying suggest that bullying is less prevalent in the educational sector [10]. In this study we have found the prevalence of workplace bullying in the sample of Kaunas teachers at the rate of $4.1 \%$. In the sample of Polish teachers where the frequency and the type of hostile behavior were measured using locally developed questionnaire, the prevalence of workplace bullying was at the rate of 7\% [24], in the Croatian sample every 5 th teacher $(22.4 \%)$ declared exposure to different kinds of harassment during last 12 months and every 10th (11.5\%) one complained about having psychological health problems caused by work [25].

The scientific literature suggests that healthcare workers, especially nurses in mental health care and intensive care units have high rates of post-traumatic stress symptoms due to emotionally stressful work, including witnessing patients' deaths, suffers and also physical violence they experience from patients [26]. The meta-analysis on cross-sectional and longitudinal data obtained during the studies conducted worldwide confirms that workplace bullying is a strong predictor of stress-related psychological complaints, post-traumatic stress symptoms, anxiety and depression [27]. The study carried out in Italy affirmed that bullying mediated the relationship between job demands and post-traumatic symptoms [28].

The results of a prospective study run in the sample of German junior physicians suggested bi-directional associations between victimization from workplace bullying and depressive symptoms [29]. Our study revealed that concomitant exposure to 22 negative acts at the workplace was significantly associated with psychological distress, post-traumatic stress symptoms among family physicians, internal medicine departments' nurses and secondary school teachers even after adjustment to adverse psychosocial job characteristics (high job demands, low job control and low social support at work) and threatening life events. In the representative sample of German teachers psychological distress was assessed for nearly $1 / 3$ (29.8\%) of teachers [30].

The study on exposure to psychosocial work factors in 31 European countries excluded Lithuania as one of the countries with higher prevalence of exposure to psychosocial work factors which also included workplace violence as compared to Northern Europe [10]. The aforementioned results confirm that working conditions are critical in terms of workplace bullying, especially in the healthcare sector, and it is therefore essential to institute a zero-tolerance approach to all forms of bullying. It is important to increase the awareness of employees, to establish the nationwide strategies or local organizational policies that would provide guidance to 
employees subjected to any type work violence on how to cope with the experienced adverse situations.

Moreover, it is necessary to continue research on workplace bullying in a wider spectrum of sectors and occupations and to identify the high-risk groups. We hope that the results of this study will contribute to acknowledgment of the existing problem and the development and implementation of measures to prevent workplace bullying.

To our best knowledge, this is the first study investigating the prevalence of bullying using the operational method, exploring the variety of bullying behavior and the differences among female-dominated occupations in Lithuania.

The strengths of the study have been that our sample size has been relatively large to produce reliable results. We have surveyed nearly 1/5 (approximately 17.1\%) of Kaunas secondary school employees, around $41 \%$ of nurses working in the internal medicine departments in Kaunas hospitals and $65.7 \%$ of family physicians representing public and private out-patient clinics. We have also used reliable and valid instruments for measuring study variables.

Nevertheless, we should admit and mention several limitations of this research. Firstly, due to a crosssectional design of the study we should be cautious while interpreting the results as we can only describe correlations, but not prove the causal relationships between the variables. Hence, longitudinal studies should be conducted to gain more knowledge about the causality of the relationships between workplace bullying, psychological distress and post-traumatic stress symptoms. Secondly, the collected data in the used questionnaire is based on self-reports which raises the possibility of reporting bias.

\section{CONCLUSIONS}

Health care sector is greatly affected by workplace bullying. Lower prevalence of bullying behavior has been found among teachers. Exposure to bullying behavior has been associated with mental health problems for all 3 occupations. Preventive measures are necessary to improve psychosocial work environment conditions in healthcare and educational institutions in Lithuania.

\section{ACKNOWLEDGMENTS}

Technician Mindaugas Malinauskas created the data set and statistician Marius Juknevicius provided help in the statis- tical analysis. The Chair of the Laboratory Prof. Abdonas Tamosiunas provided general support.

\section{REFERENCES}

1. World Health Organization. Mental health policies and programmes in the workplace. Geneva: The Organization; 2005.

2. Salin D. Risk factors of workplace bullying for men and women: The role of the psychosocial and physical work environment. Scand J Psychol. 2015;56:69-77, https://doi. org/10.1111/sjop.12169.

3. Nielsen MB, Hetland J, Matthiesen SB, Einarsen S. Longitudinal relationships between workplace bullying and psychological distress. Scand J Work Environ Health. 2012;38(1):38-46, https://doi.org/10.5271/sjweh.3178.

4. Matthiesen SB, Einarsen S. Psychiatric distress and symptoms of PTSD among victims of bullying at work. $\mathrm{Br}$ J Guid Counc. 2004;32(3):335-56, https://doi.org/10.1080/ 03069880410001723558.

5. Einarsen S, Hoel H, Zapf D, Cooper CL. The concept of bullying and harassment at work: The European tradition. In: Einarsen S, Hoel H, Zapf D, Cooper CL, editors. Bullying and harassment in the workplace. London: Taylor \& Francis; 2011. p. 3-39.

6. Glambek M, Skogstad A, Einarsen S. Do the bullies survive? A five-year, three-wave prospective study of indicators of expulsion in working life among perpetrators of workplace bullying. Ind Health. 2016;54:68-73, https://doi. org/10.2486/indhealth.2015-0075.

7. Ariza-Montes A, Muniz NM, Montero-Simó JM, AraquePadilla RA. Workplace bullying among healthcare workers. Int J Environ Res Public Health. 2013;10:3121-39, https://doi.org/10.3390/ijerph10083121.

8. Giorgi G, Arenas A, Leon Perez JM. An operative measure of workplace bullying: The negative acts questionnaire across Italian companies. Ind Health. 2011;49:686-95, https://doi.org/10.2486/indhealth.MS1287.

9. Mikkelsen EG, Einarsen S. Bullying in Danish worklife: Prevalence and health correlates. Eur J Work Organ Psychol. 2001;10(4):393-413, https://doi.org/10.10 80/13594320143000816.

10. Niedhammer I, Sultan-Taïeb H, Chastang JF, Vermeylen G, Parent-Thirion A. Exposure to psychosocial work factors in 31 European countries. Occup Med (Lond). 2012;62:196-202, https://doi.org/10.1093/occmed/kqs020.

11. Einarsen S, Hoel H, Notelaers G. Measuring exposure to bullying and harassment at work: Validity, factor structure and psychometric properties of the Negative Acts Questionnaire-Revised. Work Stress. 2009;23(1):24-44, https:// doi.org/10.1080/02678370902815673. 
12. Vasilavičius P. Negative acts at work experienced by nurses of healthcare institutions of Kaunas county and their correlations with self-report on personal health. Kaunas: Lithuanian University of Health Sciences; 2008.

13. Weiss DS, Marmar CR. The impact of event scale-revised. In: Wilson JP, Keane TM, editors. Assessing psychological trauma and PTSD. New York: Guildford Press; 1997. p. 399-411.

14. Creamer M, Bell R, Failla S. Psychometric properties of the impact of event scale-revised. Behav Res Ther. 2003;41(12):1489-96, https://doi.org/10.1016/j.brat.2003. 07.010 .

15. Malinauskiene V, Theorell T, Grazuleviciene R, Azaraviciene A, Obelenis V, Azelis V. Psychosocial factors at work and myocardial infarction among men in Kaunas, Lithuania. Scand J Work Environ Health. 2005;31(3): 218-23, https://doi.org/10.5271/sjweh.872.

16. Wood D. Bullying and harassment in medical schools. BMJ. 2006;333:664-5, https://doi.org/10.1136/bmj.38954. 568148.BE.

17. Kowalenko T, Walters BL, Khare RK, Compton S. Workplace violence: A survey of emergency physicians in the state of Michigan. Ann Emerg Med. 2005;46(2):142-7, https://doi.org/10.1016/j.annemergmed.2004.10.010.

18. Cheema S, Ahmad K, Giri SK, Kaliaperumal VK, Naqvi SA. Bullying of junior doctors prevails in Irish health system: A bitter reality. Ir Med J. 2005;98(9):274-5.

19. Frank E, Carrera JS, Stratton T, Bickel J, Nora LM. Experiences of belittlement and harassment and their correlates among medical students in the United States: Longitudinal survey. BMJ. 2006;333(7570):682, https://doi.org/10.1136/ bmj.38924.722037.7C.

20. Johnson SL, Rea RE. Workplace bullying: Concerns for nurse leaders. J Nurs Adm. 2009;39(2):84-90, https://doi. org/10.1097/NNA.0b013e318195a5fc.

21. Berry PA, Gillespie GL, Gates D, Schafer J. Novice nurse productivity following workplace bullying. J Nurs Scholarsh. 2012;44(1):80-7, https://doi.org/10.1111/j.1547-50 69.2011.01436.x.
22. Nielsen MB, Skogstad A, Matthiesen SB, Glaso L, Schanke Aasland M, Notelaers G, et al. Prevalence of workplace bullying in Norway: Comparisons across time and estimation methods. Eur J Work Organ Psychol. 2009;18(1):81-101, https://doi.org/10.1080/13594320801969707.

23. Losa Iglesias ME, Becerro de Bengoa Vallejo R. Prevalence of bullying at work and its association with selfesteem scores in a Spanish nurse sample. Contemp Nurse. 2012;42(1):2-10, https://doi.org/10.5172/conu.2012.42.1.2.

24. Mościcka-Teske A, Drabek M, Pyżalski J. [Experienced bullying and hostile behaviour in the workplace and symptoms of burnout in teachers]. Med Pr. 2014;65(4):535-42, https://doi.org/10.13075/mp.5893.00017. Polish.

25. Russo A, Milić R, Knežević B, Mulić R, Mustajbegović J. Harassment in workplace among school teachers: Development of a survey. Croat Med J. 2008;49:545-52, https:// doi.org/10.3325/cmj.2008.4.545.

26. Skogstad M, Skorstad M, Lie A, Conradi HS, Heir T, Weisaeth L. Work-related post-traumatic stress disorder. Occ Med. 2013;63:175-82, https://doi.org/10.1093/occmed/ kqt003.

27. Verkuil B, Atasayi S, Molendijk ML. Workplace bullying and mental health: A meta-analysis on cross-sectional and longitudinal data. PLoS ONE. 2015;10(8):e0135225, https://doi.org/10.1371/journal.pone.0135225.

28. Balducci C, Fraccaroli F, Schaufeli WB. Workplace bullying and its relation with work characteristics, personality, and post-traumatic stress symptoms: An integrated model. Anxiety Stress Coping. 2011;24(5):499-513, https://doi. org/10.1080/10615806.2011.555533.

29. Loerbroks A, Weigl M, Li J, Glaser J, Degen C, Angerer P. Workplace bullying and depressive symptoms: A prospective study among junior physicians in Germany. J Psycosom Res. 2015;78(2):168-72, https://doi.org/10.1016/ j.jpsychores.2014.10.008.

30. Bauer J, Unterbrink T, Hack A. Working conditions, adverse events and mental health problems in a sample of 949 German teachers. Int Arch Occup Environ Health. 2007;80:442-9, https://doi.org/10.1007/s00420-007-0170-7.

This work is available in Open Access model and licensed under a Creative Commons Attribution-NonCommercial 3.0 Poland License / Ten utwór jest dostępny w modelu open access na licencji Creative Commons Uznanie autorstwa - Użycie niekomercyjne 3.0 Polska - http://creativecommons.org/ licenses/by-nc/3.0/pl/deed.en. 